\title{
A PROPOSAL FOR IN-PLANE STABILITY DESIGN OF STEEL FRAMED STRUCTURES
}

Fumio NISHINO* and Walid ATTIA**

\begin{abstract}
One aspect not considered seriously in the revisions of the structural steel design codes is the adoption of design analyses where the use of computers is presupposed. A procedure to determine effective length is presented for in-plane stability failure of frames by utilizing eigenvalue analysis of the tangential stiffness matrix, for which the use of computers is essential. Determination of the effective lengths by the eigenvalue analysis encounters one difficulty when there exist members in a frame subject to very small amounts of internal compression. The load carrying capacity of the frame could be determined by these members resulting in unrealistically small capacity. This difficulty was overcome by introducing an amplification factor concept. The proposed procedure is clear and applicable for any frame including one with non-prismatic members.
\end{abstract}

Keywords : beam-column, codes, effective length, frame stability

\section{INTRODUCTION}

It has been known for many years that small displacement analysis with the assumption of linear material properties does not predict the ultimate strength of structures. Because of the lack of knowledge of structural theory in the early years and, even later when theoretical work was advanced, because of the lack of computational capability, structural design was based on linear small displacement analysis.

Design codes are revised continuously to incorporate the latest developments in structural engineering. One of the understandings when codes were revised in the past, however, seems to be that structural designs are based on linear small displacement analyses except in a few cases such as design of simple and small framed structures by the so-called simple plastic analysis ${ }^{1)}$, and of arches and suspension bridges in which the presence of initial stresses, and hence, geometric stiffness are considered in the analyses.

Structural theory has developed extensively. Computing facilities have developed even more extensively and the cost of computation is getting much cheaper. It seems to be the time that efforts beyond linear small displacement analysis should be made in the analyses of practical designs, if they lead to more economical and safer structures without costing much for additional computing expenditure.

Almost all design codes specify for an unbraced

* Member of JSCE, Ph. D., Professor, Department of Civil Engineering, University of Tokyo

(Bunkyo-ku, Tokyo 113).

** D. Eng., Nippon Engineering Consultants formerly, Graduate Student, University of Tokyo. frame that the effective length of compression members shall be determined by a rational method and shall not be less than the actual unbraced length ${ }^{1)}$. The clause, however, does not specify nor suggest any method of analysis. The present codes assume that the structural analysis is made by small displacement analysis and they provide clauses or refer to charts for the determination of effective lengths of columns. These provisions or reference charts are prepared for a variety of cases as a function of the flexural rigidity of the member and those of the adjacent ones and/or the boundary conditions.

It should be noted that the effective length depends not only on the boundary conditions and the rigidities of the adjacent members, but also on the pattern of loading even for a structure with linear elastic material ${ }^{2,3)}$. This effect has been recognized many years ago and incorporated, though in very primitive way, in the German specifications ${ }^{4}$. Different effective lengths are given for the same column under different loading patterns. This dependence of the effective lengths on the loading conditions may make their determination erroneous, if they are determined by the rigidities alone, especially for members of structures such as tied arches which have to be designed under a variety of completely different loading conditions. The effective length for a member is not constant but it changes for different loading. This process of recalculation for each case of loading leads to either an economical or a safer design.

\section{NECESSITY OF DEFINING EFFECTIVE LENGTHS}

There are statements in many text books for 
design of steel structures that overall frame stability can be easily determined by the eigenvalue analysis of the tangential stiffness matrices. This, however, is true only for structures made of elastic materials. Such factors as material nonlinearity, presence of residual stresses, initial geometric imperfection and nonhomogeneity of materials in each member have to be taken into account for the evaluation of the strength of a framed structure. Since present design procedure for in-plane stability does not directly evaluate the strength considering these factors even when eigenvalue analyses are made, the eigenvalue analysis of the whole frame cannot be directly applied, but additional considerations are necessary. These factors are reflected in the evaluation of the strength by a column strength curve specified in codes with the use of the effective length or more precisely by the so-called slenderness parameter. By this reason, the result of the eigenvalue analysis of the whole structure can only be used in practical design to determine the effective lengths of the components of the framed structure. Once the effective length, and hence, the slenderness parameter are determined, the above stated effects can be incorporated in the design following the present design procedure.

This paper presents a proposal, as an extension of the past works ${ }^{2,3)}$, for a rational method to determine the effective length by utilizing an eigenvalue analysis of the tangential stiffness matrix. This determination proposed by Nishino et al. ${ }^{2,3)}$ has been already adopted in the German specifications $^{5}$. However, the application of the effective lengths so determined in design of a complex frame is not straight forward, but some additional considerations are necessary which are also presented in this paper.

Because of the difficulty of defining a member in a framed structure, the effective length is defined in this proposal at each section along the lengths of the members, as defined in the previous works ${ }^{2,3)}$, so that the safety for in-plane stability failure can be checked at each section. Because of the availability of computers, such as the so-called engineering work stations, the proposed analysis seems no longer a burden even at present for the designs of complex framed structures, although the effective length at a section is not constant but changes with the change of loading.

Similar attempts made in the past ${ }^{2,3)}$ and adopted in specifications ${ }^{5}$, however, had one problem in practical application. If there exist sections in a framed structure subject to very small amounts of internal axial compression, there is a possibility that the load carrying capacity of the frame is determined by these sections resulting in an unrealistically small load carrying capacity. Major aim of this study is to solve this problem. The utilization of an eigenvalue analysis would be the first step of employing a finite displacement analysis in the design procedure. Although no proposal is made in this paper, the next step is to utilize a more accurate nonlinear analysis ${ }^{6)}$.

When the design codes assume that a structural design is made with the assumptions of small displacement and linear elasticity, the codes include a number of clauses to consider nonlinear effects and imperfections for estimating the ultimate carrying capacity. Limiting to in-plane stability failure of a member in framed structures, the so-called interaction formula adopted in many codes is one of the typical examples of these clauses. When a member subject to external axial forces and equal amount of moments at both ends resulting in single curvature, the formula can be written in a general form $^{7)}$ by separating the socalled safety factor $v$ from the allowable stress ${ }^{8)}$, or by multiplying both the denominators and numerators by cross-sectional area and section modulus after separating the safety factor as

$$
\begin{aligned}
& v\left[\frac{\sigma_{a}}{\sigma_{c u}}+\frac{\sigma_{b}}{\sigma_{y}\left(1-v \frac{P}{P_{c r}}\right)}\right] \leq 1 \quad \text { or } \\
& v\left[\frac{P}{P_{u}}+\frac{M}{M_{y}\left(1-v \frac{P}{P_{c r}}\right)}\right] \leq 1 \cdots \cdots \cdots \cdots \cdots(1),(2)
\end{aligned}
$$

where $\sigma_{a}, \sigma_{b}, P, M=$ axial and bending stresses, internal axial force, all positive in compression, and bending moment, respectively, evaluated by the small displacement analysis under design loads ; $\sigma_{c u}, \sigma_{y}, P_{u}, M_{y}=$ ultimate axial and yield strengths, ultimate carrying capacity for axial compression, all positive in compression, and yield moment, respectively ; and $P_{c r}=$ Euler load in the plane of stability, again positive when a compressive internal force results. The ultimate axial strength is evaluated as a function of effective length for prismatic pin-ended columns considering the effects of geometric nonlinearity, and geometric and material imperfections including the presence of residual stresses. The second denominator of the second term is the correction term for the evaluation of the bending stress due to the geometric nonlinear effect. When $v$ is placed inside the brackets, $v P$ and $v M$ can be regarded as internal forces resulting from the factored loads. The factor $v$ changes its value for different limit states and load combinations. The formula is reasonably accurate for the estimation of the ultimate carrying capacity of a simply supported 
beam-column with equal external moments applied at both ends. The equation is assumed, with the incorporation of additional correction factors, as applicable in any other loading cases and boundary conditions $\mathrm{s}^{6,7)}$, which increases the error though efforts are being paid to minimize $i t^{9}$.

\section{DETERMINATION OF EFFECTIVE LENGTH FOR IN-PLANE STABIL. ITY BY EIGENVALUE ANALYSIS OF THE WHOLE STRUCTURE}

The tangential stiffness equation of a short prismatic beam-column element $p$, which is free from distributed external axial forces, and hence, the internal axial force is constant, can be expressed as

$$
\Delta \boldsymbol{f}_{p}=\left[\left(\boldsymbol{k}_{e}\right)_{p}+\left(\boldsymbol{k}_{g}\right)_{p}\right] \Delta \boldsymbol{u}_{p}=\left[\left(\boldsymbol{k}_{e}\right)_{p}+N_{p}\left(\widehat{\boldsymbol{k}}_{g}\right)_{p}\right] \Delta \boldsymbol{u}_{p}
$$

where ()$_{p}=$ quantities for element $p$ and for section $p$ later in this paper ; $\left(\boldsymbol{k}_{e}\right)_{p}=$ elastic stiffness matrix ; $\left(\boldsymbol{k}_{g}\right)_{p}=N_{p}\left(\boldsymbol{k}_{g}\right)_{p}=$ geometric stiffness matrix which is expressed as a product of internal axial force $N_{p}$ under design loads and a matrix which is not a function of the internal axial force $\left(\widehat{\boldsymbol{k}}_{g}\right)_{p} ; \boldsymbol{f}_{p}$ and $\boldsymbol{u}_{p}=$ vectors of end forces and corresponding end displacements, respectively ; and $\Delta=$ notation to indicate increments.

The critical axial end loading for an elastic prismatic member $p$ for a variety of boundary conditions known as Euler buckling load can be written as

$$
\left(P_{c r}\right)_{p}=\pi^{2} \frac{E I_{p}}{\left(L_{p}^{e}\right)^{2}}
$$

where $E=$ modulus of elasticity ; and $I_{p}, L_{p}^{e}=$ moment of inertia and effective length of the member, respectively.

The small displacement analysis for an endloaded member results in the internal axial force being equal in magnitude to the external loading applied at both ends. This leads to

$$
\left(N_{c r}\right)_{p}=-\left(P_{c r}\right)_{p}
$$

where $\left(N_{c r}\right)_{p}=$ internal axial force (positive in tension) when the member becomes unstable.

By employing the effective length $L_{p}^{e}$, Eq.(4) is applicable to any free body cut out from a framed structure, and hence Eq.(4) can be understood as the condition for a short element or an arbitrary section $p$ of a member or of a frame to become unstable. Then, in view of Eqs.(4) and (5), the effective length of a section $p$ of a framed structure can be defined as

$$
L_{p}^{e}=\pi \sqrt{\frac{E I_{p}}{-\left(N_{c r}\right)_{p}}}
$$

In the design procedure proposed in this paper, the design loads are increased by a factor $\alpha$ until the frame becomes unstable. Since geometrical nonlinear responses due to the increase of external loading are already considered in Eqs.(1) and (2), linear analysis is sufficient to evaluate responses due to external loading. Therefore, multiplying $N_{p}$ of Eq.(3) by the undetermined coefficient $\alpha$ for each element and assembling them for all elements of a structure, the tangential stiffness matrix of the structure $\boldsymbol{K}_{t}$ is expressed as

$$
\boldsymbol{K}_{t}=\left[\boldsymbol{K}_{e}+\alpha \boldsymbol{K}_{g}\left(N_{p}\right)\right]
$$

where $\boldsymbol{K}_{e}=$ elastic stiffness matrix of small displacement theory ; and $\alpha \boldsymbol{K}_{g}\left(N_{p}\right)=$ geometric stiffness matrix when the structure becomes unstable.

Substituting $N_{p}$ determined by the small displacement elastic analysis into Eq.(7), the undetermined coefficient $\alpha$ when a frame becomes unstable can be obtained as the smallest eigenvalue of the tangential stiffness matrix. The internal axial force when the structure becomes unstable can then be expressed as

$$
\left(N_{c r}\right)_{p}=\alpha N_{p}
$$

The so-called slenderness parameter, referred to as $\lambda$, is defined as

$$
\lambda=\frac{1}{\pi} \frac{L^{e}}{r} \sqrt{\frac{\sigma_{y}}{E}} \text {. }
$$

where $r=$ radius of gyration. The radius of gyration at section $p$ is defined by the moment of inertia $I_{p}$ and the cross-sectional area $A_{p}$ as

$$
r_{p}=\sqrt{\frac{I_{p}}{A_{p}}}
$$

Substituting Eqs.(6) and (10) into Eq.(9) results in a slenderness parameter defined at a section $p$ as

$$
\lambda_{p}=\sqrt{\frac{A_{p} \sigma_{y}}{-\left(N_{c r}\right)_{p}}}
$$

\section{SECTIONS WITH SMALL VALUES OF AXIAL FORCE}

Since the stiffnesses of all members of a structure, the boundary conditions and the loading conditions are considered, the definition of the effective lengths by Eq.(6) together with Eq.(8) and $\alpha$ determined by the eigenvalue analysis of the tangential stiffness matrix of a structure should be much more accurate than those determined by the conventional methods using stiffnesses of the adjacent members. The stability design procedure using this definition, however, has one drawback when there exist sections subject to small amounts of internal axial compression under design loads.

Consider a simply supported frame subject to horizontal loads $F_{h}$ such as wind loading in addition to the usual gravity loading $F_{v}$ as shown in Fig.1. Both positive and negative wind forces, though the 


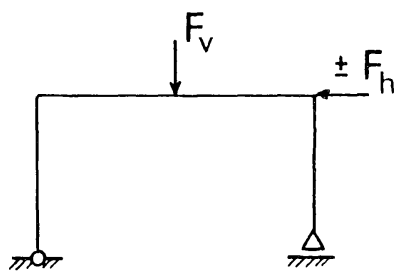

Fig.1 Simply suppored frame subject to horizonal load of small magnitude

latter is unlikely in practice, are considered for demonstration purposes representing forces in the direction of the wind and suction, which is in the opposite direction of the wind.

The girder is subject only to bending moment when no horizontal loading is present. The same girder is subject to both bending moment and internal axial force when external horizontal force is present, compressive and tensile axial forces as for the cases of positive and negative $F_{h}$, respectively. The stability of these two cases is determined by the vertical loading and the horizontal force, $F_{h}$. Common sense of structural engineering suggests that the load carrying capacity of these two cases, and hence, the designs for a given loading $F_{v}$ cannot be much different when the magnitude of the external horizontal force is extremely small.

The proposed procedure could lead to a very long effective length for a section subject to a small value of internal axial compressive force such as the case with a small value of positive horizontal force in Fig.1. Incorporating such a design formula as Eq.(1) or (2) to check the safety of a structure, the proposed procedure might lead to a much different load carrying capacity depending on the sign of the internal axial force in the girder.

Noting that the internal tensile axial force does not play any role in the column stability, the value of $\lambda_{p}$ is taken as equal to zero when the internal axial force is in tension or zero. For an element with a large value of slenderness parameter, the ultimate axial compressive strength $\sigma_{c u}$ is well represented by the Euler buckling load of Eq.(4) divided by the cross-sectional area. Hence, in view of Eqs.(4), (5) and (11), the strength of a section subject to a very small amount of internal compressive force is expressed as

$$
\frac{\sigma_{c u}}{\sigma_{y}}=\frac{1}{\left(\lambda_{p}\right)^{2}}
$$

Noting that $\sigma_{a}=-N_{p} / A_{p}$, substituting Eqs.(8) and (12) into Eq.(11) leads the first term of Eq.(1) for the section with a small value of compression to

$$
\frac{\sigma_{a}}{\sigma_{c u}}=\frac{1}{\alpha}
$$

whereas if the internal axial force $N_{p}$ changes from an infinitesimally small value of compression to tension, the ultimate strength $\sigma_{c u}$ becomes equal to $\sigma_{y}$ and $\sigma_{a}$ is close to zero, and hence this term becomes

$$
\frac{\sigma_{a}}{\sigma_{c u}}=\frac{\sigma_{a}}{\sigma_{y}} \approx 0
$$

The change of magnitude of the second term of Eq.(1) or (2) is insignificant for the change of the axial force from tension to compression or vice versa when its absolute magnitude is small compared to $P_{c r}$. On the other hand, the magnitude of the first term changes in general with the change of the sign of internal axial force even if its magnitude is infinitesimally small. Except for the case when the value of $\alpha$ is very large, the magnitude of the first term changes significantly. Because of this, when a small axial force changes its sign at a section, the carrying capacity of that section could also change significantly as shown later in Numerical Example (3). As stated earlier, common sense suggests that there should not be much difference in the carrying capacity in both cases. Hence, some sort of preventative technique is necessary for the proposed effective length to be used in practical design when the internal axial force is in compression of very small magnitude. Such a preventative method should lead to a safer design.

To avoid a very long effective length at each section with a small value of internal axial force, its value is amplified by multiplying it by a factor $k_{p}$ larger than or equal to unity as

$$
\bar{N}_{p}=k_{p} N_{p} \quad\left(k_{p} \geq 1\right)
$$

where $\left({ }^{-}\right)=$quantities for a frame with the adoption of Eq.(15) for some parts of the frame. The amplification factor $k_{p}$ being equal to unity is included so that Eq.(15) is applicable for all sections including the sections where no amplification of internal forces is necessary. Employing these values in Eq.(7), the modified tangential stiffness matrix $\overline{\boldsymbol{K}}_{t}$ by the use of $\bar{N}_{p}$ is written as

$$
\overline{\boldsymbol{K}}_{t}=\left[\boldsymbol{K}_{e}+\bar{\alpha} \boldsymbol{K}_{g}\left(\bar{N}_{p}\right)\right]
$$

The smallest eigenvalue $\bar{\alpha}$ of the tangential stiffness matrix of Eq.(16) decreases its magnitude from $\alpha$ with increasing value of each $k_{p}$. The modified slenderness parameter by the amplification factor $k_{p}$ at each section with small axial compression is evaluated in the same way as for Eq.(11) as

$$
\bar{\lambda}_{p}=\sqrt{\frac{A_{p} \sigma_{y}}{-\left(\bar{N}_{c r}\right)_{p}}} \cdot
$$

Since the amplification of the internal forces is made only for elements with small axial compress- 


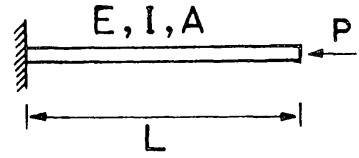

Fig.2 cantilever column (example 1.)

ion, its effect for $\bar{\alpha}$ is expected to be very small and insignificant. Because of this, the magnitude of $\bar{\alpha} k_{p}$ and hence that of $\left(\bar{N}_{c r}\right)_{p}$ becomes larger than $\left(N_{c r}\right)_{p}$ for members with the adoption of the amplification factors. With the larger value of $\left(\bar{N}_{c r}\right)_{p}$ than $\left(N_{c r}\right)_{p}$, the value of $\bar{\lambda}_{p}$ becomes smaller than $\lambda_{p}$ of Eq.(11). This smaller slenderness parameter leads to a larger value of ultimate compressive strength $\sigma_{c u}$ for the section $p$. The value of $\bar{\alpha}$, and hence, the load carrying capacity determined by the stability analysis decreases with the employment of $k_{p}$ for some parts of a frame, but the decrease of the overall load carrying capacity is expected to be very small for the reason stated above.

The same amplification factor can also be utilized to increase the evaluation of the carrying capacity of a structure to some members which are not necessarily subject to compression of a very small magnitude. This use is also demonstrated later in Numerical Example (2).

In view of Eq.(5) and the definition of $\left(N_{c r}\right)_{p}$, Eq.(1) can be rewritten into the following form

$$
\frac{-\left(N_{c r}\right)_{p}}{P} \geq v \frac{\left[1-v \frac{\sigma_{a}}{\sigma_{c a}}\right]_{p}}{\left[1-v \frac{\sigma_{a}}{\sigma_{c a}}-v \frac{\sigma_{b}}{\sigma_{y}}\right]_{p}} .
$$

The safety of a section is satisfied even if the value of $\left(N_{c r}\right)_{p}$ is made larger by an arbitrary amount as long as Eq.(18) is satisfied. In view of Eqs.(8) and (15), the adoption of an arbitrary amount of amplification factor $k_{p}$ is identical to an arbitrary increase of $\left(N_{c r}\right)_{p}$ satisfying Eq.(18) to $\left(\bar{N}_{c r}\right)_{p}$. This arbitrary selection of increased $\left(\bar{N}_{c r}\right)_{p}$ can be repeated until a satisfactory optimum design is made under given loading. The employment of the amplification factor $k_{p}$, and hence the use of Eq.(17) leads to a safer design as long as $\left(N_{c r}\right)_{p}$ at each section satisfies Eq.(18).

\section{NUMERICAL EXAMPLES}

\section{(1) A cantilever column}

Consider a prismatic cantilever column of length $L$, subjected to an external axial force $\mathrm{P}$ at the free end as shown in Fig.2. It is well known that the effective length of this column is $2 L$. This example is to show that, when the column is divided into many elements of arbitrary lengths, the proposed procedure results in the effective length of $2 L$ for each elements.

Treating the column as one element and imposing boundary conditions at the fixed end, the tangential stiffness equation can be written using the well known stiffness matrix including the geometric matrix as

$$
\left\{\frac{E I}{L^{3}}\left[\begin{array}{cc}
12 & -6 L \\
-6 L & 4
\end{array}\right]-\alpha \frac{N}{L}\left[\begin{array}{cc}
6 / 5 & L / 10 \\
L / 10 & 2 L^{2} / 15
\end{array}\right]\right\} \Delta \boldsymbol{u}=0
$$

Solving for the smallest positive eigenvalue and substituting it into Eq.(8) and then Eq.(6) give effective length of $2 L$ with a small amount of error inherent in the stiffness matrix evaluated by the finite element integration technique with a coarse mesh as for this case.

One of the proposals of this paper is to define the effective length at a section. In practice, the stiffness analysis cannot be made for a structure with an infinite number of elements, and hence the effective length at a section has to be understood as that for a short element. In this meaning the above analysis implies when the section is represented by one element with the length $L$, the effective length is $2 L$. If the cantilever is divided into two elements of any lengths, similar analysis gives again effective length of $2 L$ for both elements. It is noted that dividing the column into many elements of arbitrary lengths does not change the effective length, and hence, the slenderness parameter for each of these divided elements.

For the design of a real steel column, the effects of material nonlinearity, and presence of residual stresses and initial imperfection have to be included in the evaluation of the carrying capacity of the column. This is made by a column strength curve specified in the codes with the use of the slenderness parameter. Regardless of the selection of the number of elements including two extreme cases of one element and an infinitively large number of elements, i.e., sections, the slenderness parameter of an element, or a section, is identical and hence the proposed design procedure results in an identical design for a given load.

\section{(2) A stepped cantilever column}

No clear procedure is specified for designing stepped columns in the design codes presently in use though the German code ${ }^{5}$ implies that stability checks are necessary for the two elements. The situation is the same for columns with variable moment of inertia. This example is presented to show that the proposed procedure including the use of amplification factor is applicable to the design of these types of columns and the results of its application.

Consider a stepped cantilever column subjected 


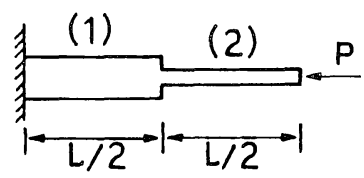

Fig.3 Stepped cantilever column (example 2.)

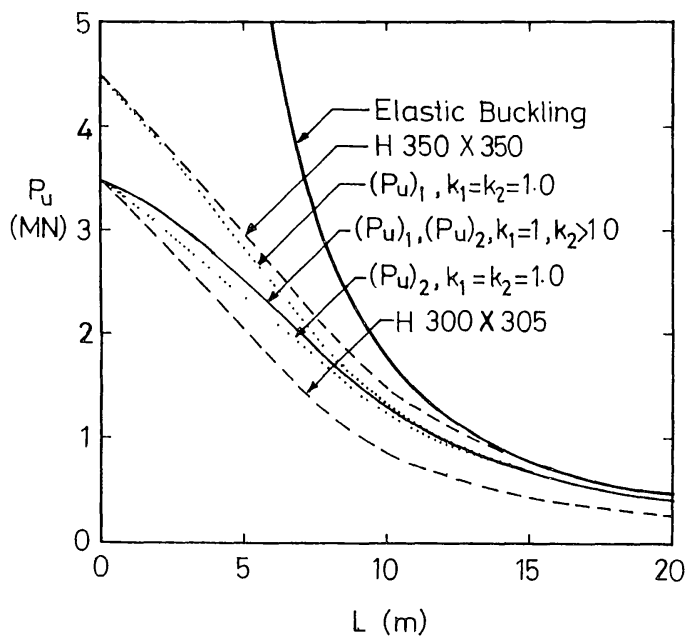

Fig.4 Ultimate load of the stepped cantilever column

to an external axial force at the free end as shown in Fig.3. The column consists of two different sections of equal lengths. From the list of column type hot rolled sections ${ }^{10)}$, H 350 X 350 and H 300 X 305 were selected arbitrarily for the purpose of demonstration for the elements (1) and (2), respectively. The value of the modulus of elasticity was selected as $212000 \mathrm{MPa}$.

The proposed method is first applied to this stepped column to evaluate the effective lengths of both elements. The elastic buckling loads determined by both elements using these effective lengths are equal and the same as the buckling load of the stepped column itself. This is obvious by noting that $N_{p}$ and hence $\left(N_{c r}\right)_{p}$ are the same for both elements and that substituting this $\left(N_{c r}\right)_{p}$ into Eq.(6) and then into Eq.(4) results in the same value of elastic buckling load regardless of the difference of moment of inertia of the two elements.

The ultimate compressive loads were evaluated for both elements after calculating the slenderness parameters by the proposed procedure and using the column strength curve in the Japanese design code $^{11)}$. The results are shown in Fig.4 in which $\left(P_{u}\right)_{1}\left(k_{1}=k_{2}=1.0\right)$ and $\left(P_{u}\right)_{2}\left(k_{1}=k_{2}=1.0\right)$ are the ultimate compressive loads for the elements (1) and (2), respectively. Fig. 4 shows that the element (2) gives smaller ultimate load than that of the element (1). Therefore, the load carrying capacity of the column is equal to the ultimate load of the element (2) when the original proposed method for the effective length of each arbitrary divided element of a structure is applied. This smaller carrying capacity can be increased by incorporating an amplification factor $k_{2}$ larger than unity for the internal axial force of the element (2) without loosing safety, as explained earlier.

Since the carrying capacity of this stepped column is determined by the smaller ultimate load of the two elements by the proposed procedure, it is the largest when the ultimate loads of the two elements coincide. An arbitrary selection of the amplification factor $k_{2}$ for the element (2) was repeated until the preceding condition was satisfied and the results are shown in Fig. 4 by the curve $\left(P_{u}\right)_{1}=\left(P_{u}\right)_{2}\left(k_{1}=1.0, k_{2}>1.0\right)$. When the length of this stepped column approaches zero, the carrying capacity is determined by the yield strength of the cross section rather than stability. Because of this, the carrying capacity of the stepped column with the adoption of an optimum amplification factor approaches the yield load of a prismatic column made of $\mathrm{H} 300 \times 305$ as the length of the stepped column approaches zero which is the same with the ultimate load of the element (2) when $k_{2}=1.0$. With the adoption of the optimum amplification factor, the carrying capacity of the stepped column exceeds the ultimate load $\left(P_{u}\right)_{2}\left(k_{1}=k_{2}=1.0\right)$ of the element (2) and approaches the ultimate load $\left(P_{u}\right)_{1}\left(k_{1}=k_{2}\right.$ $=1.0$ ) of the element (1) with increasing the length.

For reference, Fig.4 also shows the elastic buckling load of the stepped column and the carrying capacities of the prismatic columns made of H 350 X 350 and $\mathrm{H} 300 \times 305$, respectively. The two curves for the elements (1) and (2) with $k_{1}$ $=k_{2}=1.0$ fall within the range between the carrying capacity curves of these two prismatic columns and the curve with the optimum amplification factor $k_{2}>1.0$ falls within the range of the two curves for the elements (1) and (2) with $k_{1}=k_{2}=$ 1.0 .

The German code $\mathrm{e}^{5}$, if applied as it implies, results in the design strength of this column equal to $\left(P_{u}\right)_{2}$ for $k_{1}=k_{2}=1.0$ which is smaller than the strength proposed in this study.

The same procedure can be applied for a column with variable moment of inertia by modifying it physically into a stepped column consisting of short elements. Since no procedure is specified for columns with variable moment of inertia, the present custom for the design of this column is to change it into a prismatic column with the same elastic buckling strength and use the column 


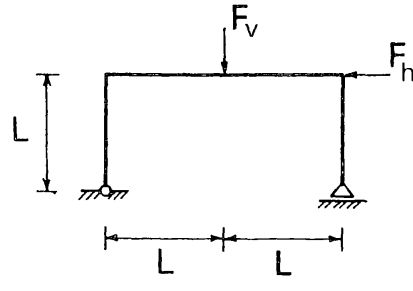

(a)

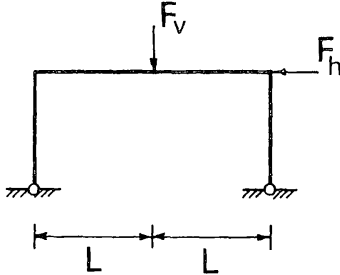

(b)

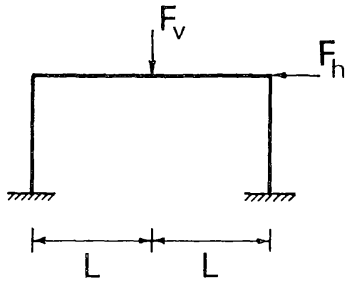

(c)

Fig.5 One bay one story frames (example 3.)

Table 1 Values of sectional properties of girder and columns of example (3)

\begin{tabular}{c|c|c|c}
\hline Element & Case (a) & Case (b) & Case (c) \\
\hline Girder : I $\left(10^{6} \mathrm{~mm}^{4}\right)$ & 270.29 & 125.56 & 108.55 \\
\hline $\mathrm{S}\left(10^{3} \mathrm{~mm}^{3}\right)$ & 1005.5 & 491.1 & 427.29 \\
\hline $\mathrm{A}\left(10^{3} \mathrm{~mm}^{2}\right)$ & 7.6448 & 5.2104 & 4.8446 \\
\hline Column : I $\left(10^{6} \mathrm{~mm}^{4}\right)$ & 2.1924 & 45.104 & 56.29 \\
\hline $\mathrm{S}\left(10^{3} \mathrm{~mm}^{3}\right)$ & 9.0099 & 182.05 & 226.17 \\
\hline $\mathrm{A}\left(10^{3} \mathrm{~mm}^{2}\right)$ & 0.68852 & 3.1229 & 3.4887 \\
\hline
\end{tabular}

Note: $1 \mathrm{~mm} .=0.03937 \mathrm{in}$.

strength curve for this equivalent prismatic column to evaluate the load carrying capacity, for which no rational background seems to be present. Whereas the proposed procedure can utilize the column strength curve introducing the strength at each element by its slenderness parameter rather than a single equivalent slenderness parameter. This proposed procedure is much more rational and the results are expected to be closer to the strengths of real columns.

\section{(3) Simple Plane Frames}

This example is presented to show the improvement of the difficulty presented in previous works $\mathrm{s}^{2,3)}$ by the introduction of the amplification factor $k_{p}$ when there exist elements subject to small values of axial compression in simple one bay one story frames.

The in-plane behavior of three simple frames with different supports was analyzed under a vertical load in the middle of the girder, as shown in Fig.5. The same geometrical configuration was used for the three cases with $L=3000 \mathrm{~mm}$. The values of the moment of inertia in the three cases were determined together with the cross-sectional areas and the sectional moduli by using the empirical formulas proposed in Ref. 12) under the condition that the carrying capacity of the frame determined at a critical section of each of the three members is identical, i.e. a fully stressed design, under vertical load alone. The values of the moment of inertia, the sectional area and the sectional modulus of the girder and both columns are shown in Table 1 for the three cases. The values of yield strength and modulus of elasticity were selected as $235 \mathrm{MPa}$ and $212000 \mathrm{MPa}$, respectively and a safety factor $v$ of 1.7 was employed. This safety factor can be also understood as a load factor as explained earlier. Since the purpose of this example is to demonstrate the proposed procedure, no serious attention was paid to the selection of this value of $v$.

A horizontal force with variable magnitude and changing direction is then applied, in addition to the vertical load. The carrying capacities determined at the critical sections of the girder and the two columns are computed accordingly. The slenderness parameter of the girder and the two columns are evaluated, both with and without the amplification factor $k_{p}$. The interaction formula as given in Eq.(1), which is identical to Eq.(2), is employed as the safety criterion.

When the amplification factor is not adopted, the carrying capacity determined by the girder is different when a small value of internal axial force with different signs is present. Figs.6 (a) (c) show the load carrying capacity determined at each critical section of the girders and the two columns for the three frames, respectively. The ordinate is the carrying capacity of the girder and the two columns, and the abscissa is the ratio of the horizontal force to the vertical force.

The lowest envelope of all curves determines the 


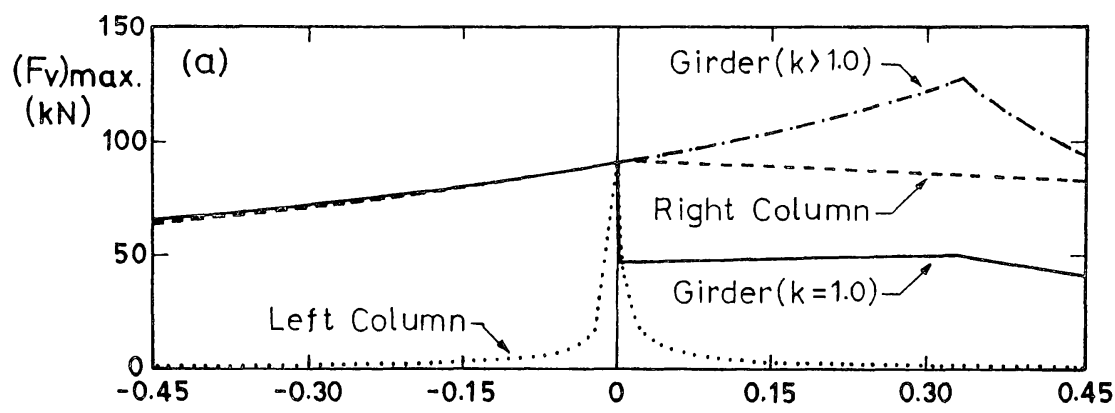

(a) Simply Supported frame

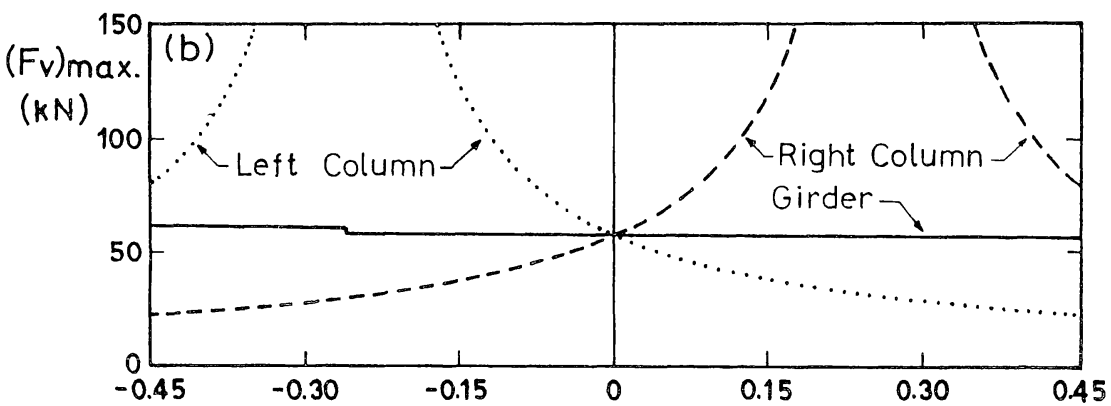

(b) Hinged Supported frame

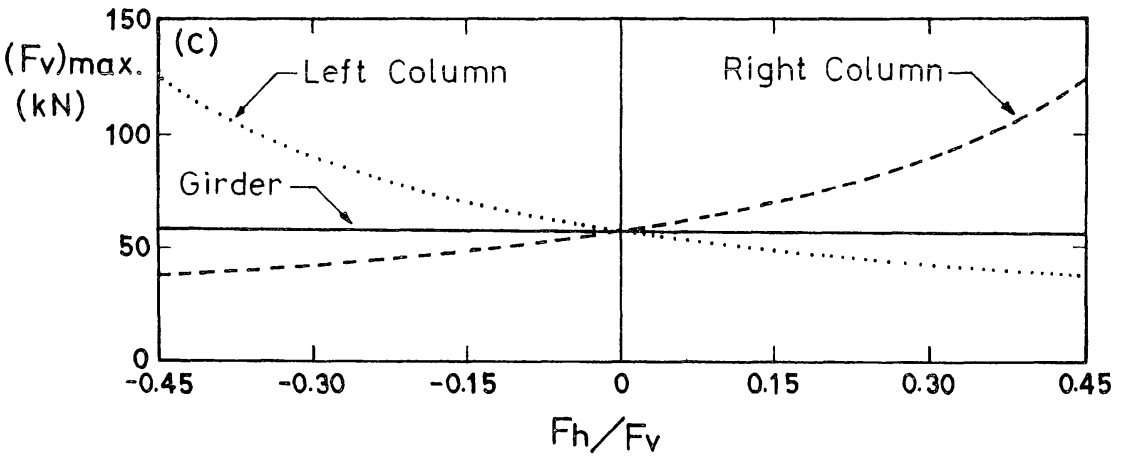

(c) Fixed Supported frame

Fig.6 Carrying capacity of one bay one story frames

carrying capacity of each frame by this proposed design method when $F_{h}$ is changed. Since an optimum design is made under $F_{v}$ alone, the carrying capacity of each frame determined at the critical sections of the two columns and the girder is identical when $F_{h}=0$, while it is determined in the case of Fig.5 (a) by the carrying capacity of the critical section of the left column for almost all the range of $F_{h} / F_{v}$. As can be seen from Fig. 6 (a), the carrying capacity of the girder, when $k=1$, changes abruptly when the axial force in the girder changes from tension to compression and it determines the carrying capacity of the frame for the range of $F_{h} / F_{v}$ between 0 . and 0.0032 . At the same time, the figure shows that, when $k>1$, the carrying capacity is determined by the left column. The value of $k$ is determined by the condition that the ultimate carrying capacity determined by one of the three elements, i.e. the lower envelope of the three curves becomes the maximum. For the range where the carrying capacity of the frame is determined by that of the girder, the amplification factor should be applied to the girder so that the carrying capacities of the girder and the left column become equal.

For demonstration purposes, the value of $k$ was selected for the entire positive range of $F_{h} / F_{v}$ to make the carrying capacity of the girder maximum. 


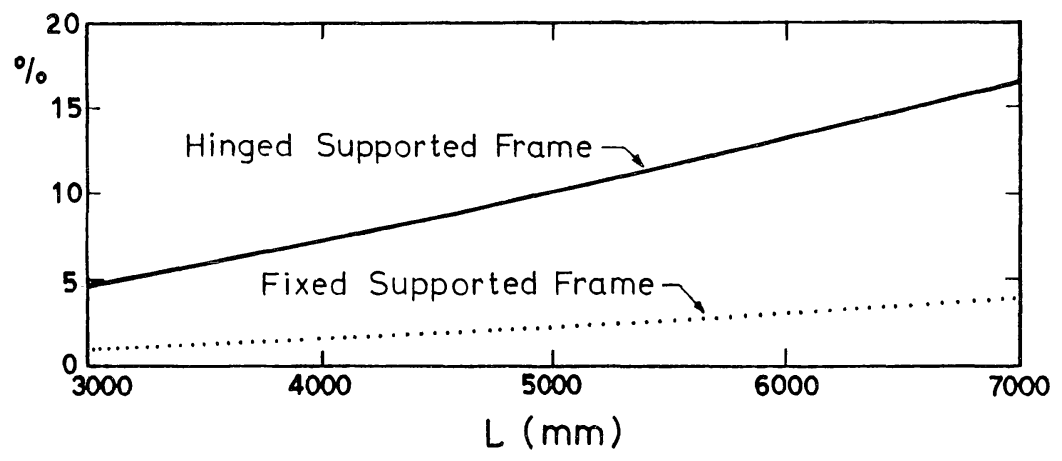

Fig.7 Difference in girder's carrying capacity for cases (b) and (c) by the change of sign of internal axial force

The resulting carrying capacity of the girder is shown in Fig.6 (a) by the dashed curve. It is noted that the carrying capacity of the girder with this amplification factor becomes continuous even when the internal axial force changes its sign. Meanwhile, the carrying capacities of the two columns decrease but their changes are insignificant. The carrying capacity of the girder has a peak value when the maximum value of the bending moment in the girder is minimum. Similar peaks take place in the carrying capacity curves of the columns for all the three frames when the maximum values of the bending moment in the columns are minimum.

Since reasonably large axial compression is present in the girder at $F_{h}=0$ for the frames of Figs.5 (b) and (c), no such differences are present in Figs.6 (b) and (c) at $F_{h}=0$. The internal axial force becomes equal to zero and hence changes its sign when $F_{h} / F_{v}=-0.25934$ and -0.50604 for the frames of Figs.5 (b) and (c), respectively. The abrupt changes of the carrying capacities determined by the critical sections of the girders similar to that of the frame of Fig.5 (a) at $F_{h}=0$ is present for the other two frames when the internal axial force changes its sign. As can be seen in Fig.6 (b), the magnitude of this abrupt change, however, is very small for the frame of Fig.5 (b) and it occurs, with a much smaller value, outside the considered range of $F_{h} / F_{v}$ for the frame of Fig.5 (c).

These insignificant differences in the carrying capacities of the girders of the frames of Figs.5 (b) and (c) are due to the presence of large values of bending stresses as a result of the considered dimensions of the frames resulting in a large value of $\alpha$. For the two frames, the share of the axial stress term, i.e. the first term of Eq.(1), is very small compared with the share of the bending stress term, i.e. the second term. The change of the geometry changes the shares of the first and second terms of Eq.(1) resulting in a difference of the value of $\alpha$, and hence, of the carrying capacity when the internal axial force changes its sign. To demonstrate this phenomenon, the heights of both columns were increased without changing the sectional properties of all the three elements. When the internal force changes its sign, the difference in the carrying capacity at a critical section of the girder increases with increasing height. The decrease of the carrying capacity when the internal axial force changes from tension to compression is computed for these two cases by changing the height and the results are shown in Fig.7. This decrease can be reduced to zero by employing the proposed amplification factor as to be shown below for the case of the frame of Fig.5 (a). These examples, though they are very simple, show the possible necessity of the proposed employment of the amplification factor when members subject to small internal axial force are present.

\section{SUMMARY AND CONCLUSIONS}

The present design of steel compression members and frames for in-plane stability failure utilizes an interaction formula between stresses due to axial compression and bending moments. A reasonably consistent safety is expected in the design by the formula provided that the effective length and hence the slenderness parameter are evaluated properly and that the variation of the bending moment is not significant along the length of an element.

A design procedure for members and frames is presented by utilizing an eigenvalue analysis of the tangential stiffness matrix and by defining the effective length at each section along the length of the members so that safety for in-plane stability failure can be checked at each section.

The procedure has three main advantages compared to the conventional design procedure. Firstly, evaluating the slenderness parameter of the 
member using eigenvalue analysis means including not only the boundary conditions and the rigidities of the adjacent members, but also the pattern of loading.

Secondly, safety check at sections implies application of Eq.(1) or (2) for the case of a member with equal end moments, i.e. the bending moment is constant along the length of the member, so that a better accuracy is expected compared to the case with variable distribution of bending moment along the length.

Thirdly, adopting the amplification factor concept results in increased strength and, hence, in an economical design as demonstrated in Numerical Example (2).

Additional advantage is that safety checks for both yielding and instability can be made simultaneously by one equation, present design procedure requires separate safety checks for yielding and instability, the former at all sections and the latter for each member.

A possible drawback of similar previous works for the case of a section subject to small internal axial compression was overcome by adopting the amplification factor concept, though it is most likely that the change of the signs of internal axial force may not influence the load carrying capacity greatly as shown in Figs.6 (b) and 7 of the third example. Also, the design procedure for members and frames is clear as demonstrated in the example of the stepped column for which no clear procedure was established.

Neither material nonlinearity nor the presence of residual stresses were considered but linear elasticity of the material is assumed in the proposed analysis. The essence of the proposed procedure is to convert sections or arbitrary short elements of a framed structure to equivalent pin-ended prismatic members. This conversion makes it possible to take advantage of the numerous experimental as well as theoretical results available for the strengths of the pin-ended members taking into accounts of all these material nonlinearities and imperfections.

\section{REFERENCES}

1) Specification for the design, fabrication and erection of structural steel for buildings, American Institute of Steel Construction, New York, 1978.

2) Nishino, F., Miki, C. and Suzuki, A. : Background of revision of specifications for highway bridges (Japan road association)-design of rigid frames, Bridge and Foundation Engineering, Vol.15, No.10, pp.10 13, 1981. (in Japanese).

3) Nishino, F. and Hasegawa, A. : A practical design for compression members and frames using eigenvalue analysis, Preliminary Report, IABSE Colloquium on Stability of Metal Structures, Paris, France, pp.497 500, Nov., 1983.

4) DIN 4114, Deutscher Normenausschuss, Berlin, FRG 1952. (in German)

5) DIN 18800 Stahlbauten, Bemessung und Konstruktion, DIN Deutsches Institut Für Normung E.V., Berlin, FRG, 1988. (in German)

6) Allen, H.G. and Bulson, P.S. : Background to buckling, McGraw Hill, London, Great Britain, 1980.

7) Galambos, T.V. : Guide to stability design criteria for metal structures, John Willey \& Sons, New York, 1988.

8) Nishino, F., Hasegawa, A., Miki, C. and Fujino, Y. : A fractile-based reliability structural design, Proc. of JSCE, No.326, pp.141 153, Oct., 1982.

9) Duan, L., Sohal, I.S. and Chen, W. : On beam-column moment amplification factor, Engineering Journal, American Institute of Steel Construction, Vol.26, No.4, pp.130 〜135, 1989.

10) Steel construction handbook, Society of Steel Construction of Japan, Gihoudou, Tokyo, 1985. (in Japanese)

11) Design code for steel structures-part A, structures in general, JSCE, Tokyo, Japan, 1987. (in Japanese)

12) Tabak, E.I. and Wright, P.M. : Optimality criteria method for building frames, Journal of the Structural Division, ASCE, Vol.107, ST 7, pp.1327 1342, July, 1981.

(Received January 23. 1991)

鋼構造物の面内座屈設計に関する一提案

西野文雄・Walid ATTIA

接線剛性行列の固有值解析を行って, 骨組を構成する部材の各断面で面内崩壞に対す

る有効座屈長さを決める方法を提案している. 固有值解析を用いて有効座屈長さを決め るとき, 小さな值の圧縮応力の働く断面が存在すると, その断面に対する有効座屈長さ が長くなり, 骨組の耐荷力が過小評価される場合が起る. 必要に応じて断面の圧縮応力 を拡大係数の概念を導入し，この耐荷力が過小評価される問題を解決している. 